\title{
Generative Classification of Elements of Nonverbal Communication
}

\author{
Kotov Artemy \\ Kurchatov Institute/ Moscow, Russia \\ Russian State University for the \\ Humanities/ Moscow, Russia \\ Moscow State Linguistic University / \\ Moscow, Russia \\ kotov_aa@nrcki.ru \\ Zaidelman Liudmila \\ Kurchatov Institute/ Moscow, Russia \\ Russian State University for the \\ Humanities/ Moscow, Russia \\ zaydelman_ly@nrcki.ru
}

\author{
Zinina Anna \\ Kurchatov Institute/ Moscow, Russia \\ Russian State University for the \\ Humanities/ Moscow, Russia \\ Moscow State Linguistic University / \\ Moscow, Russia \\ zinina_aa@nrcki.ru \\ Arinkin Nikita \\ Kurchatov Institute/ Moscow, Russia \\ Russian State University for the \\ Humanities/ Moscow, Russia \\ Arinlin_na@nrcki.ru
}

Abstract

We propose to use a generative model to classify nonverbal communicative movements (gestures, head and body postures, facial expressions). This model represents the communicative movement as a function of the emotional state, the communicative goal, and reference, and demonstrates the pathways of how the movement could be generated in communication. The proposed generative model distributes communicative movements based on the stimulus for their generation. We distinguish movements (a) related to the meaning of the sentence, (b) emotional uncontrolled movements and their controlled variants, (c) emotional states, simulated to influence the addressee, and (d) movements related to utterance production, expectation of feedback, or lack of feedback. This model can potentially classify the entire spectrum of nonverbal actions and can be applied to control robots and emotional computer agents.

Keywords: gestures; facial expressions; emotional expressions

DOI: $10.28995 / 2075-7182-2021-20-1095-1105$

\section{Генеративная классификация элементов невербальной коммуникации ${ }^{1}$}

Котов Артемий

Курчатовский институт;

Российский государственный гуманитарный университет;

Московский государственный лингвистический университет

Москва, Россия

kotov aa@nrcki.ru

\section{Зайдельман Людмила}

Курчатовский институт;

Российский государственный

гуманитарный университет

Москва, Россия

zaydelman_ly@nrcki.ru

\section{Зинина Анна}

Курчатовский институт; Российский государственный гуманитарный университет; Московский государственный лингвистический университет

Москва, Россия zinina_aaenrcki.ru

\section{Аринкин Никита}

Курчатовский институт; Российский государственный гуманитарный университет

Москва, Россия arinkin_na@nrcki.ru

\footnotetext{
${ }^{1}$ Исследование частично поддержано грантом РНФ, проект № 19-18-00547.
} 


\section{Аннотация}

Мы предлагаем использовать генеративную модель для классификации невербальных коммуникативных движений (жестов, положений головы и тела, мимики). Эта модель представляет коммуникативное движение как функцию эмоционального состояния, коммуникативной цели и референции, а также демонстрирует пути того, как движение может быть порождено в общении. Предложенная генеративная модель распределяет коммуникативные движения на основе стимула для их генерации. Мы различаем (а) движения, связанные со значением предложения, (б) эмоциональные неконтролируемые движения и их контролируемые варианты, (в) эмоциональные состояния, моделируемые для воздействия на адресата, и (г) движения, связанные с производством высказывания, ожиданием обратной связи или отсутствием обратной связи. Эта модель потенциально может классифицировать весь спектр невербальных действий и может быть применена для управления роботами и эмоциональными компьютерными агентами.

Ключевые слова: жесты; мимика; эмоциональные выражения

\section{1 Введение}

При общении люди сопровождают свою речь невербальными движениями: мимикой, жестами и более мелкими движениями, которые исходно не обладают знаковой функцией - облизываниями, почесываниями, изменениями позы и т. д. Разнообразие этих движений можно представить как некоторый континуум, где на одном полюсе будут находиться жесты, подобные знакам языка: обладающие фиксированной семантикой, формой (означающим) и правилами употребления (синтактикой), а на другом - неконтролируемые движения, не имеющие коммуникативной функции. Такие классификации невербального поведения хорошо известны по классическим работам Эфрона [2] и Кендона [5]. Подобные «градуальные» классификации невербального поведения развиваются в современных работах $[4,14]$.

В лингвистике традиционно основное внимание уделялось жестам, обладающим означаемым или фиксированной коммуникативной функцией $[12,14]$. Вместе с тем развитие мультимодальных корпусов открыло возможности для исследования и других типов движений: иллюстративных иконических жестов [16], невербального поведения при хезитации и т. д.

Хотя данные классификации относительно хорошо применимы при описании данных корпуса, их применение к системам синтеза жестов может вызывать трудности. Дело в том, что один и тот же жест может «двигаться» по континууму, меняя произвольность, фиксированность означаемого и референцию. Если мы наблюдаем экземпляры одного и того же движения в корпусе (например, прикладывание руки к голове), мы можем предположить, что в одном случае - это непроизвольное движение, связанное с задумчивостью, в другом случае - произвольная попытка воздействовать на адресата, например, чтобы показать неадекватность его слов (как если бы адресант говорил: $y$ меня от тебя уже голова болит!). Можно ожидать, что при повышении произвольности, жест будет обладать более выраженным означаемым (жест должен быть заметным для адресата), а также большей референцией (жест будет ссылаться на конкретное действие собеседника). Это означает, что разные механизмы, управляющие коммуникативным поведением, могут непроизвольно вызывать данное движение, либо, наоборот, использовать освоенное движение с некоторой коммуникативной целью, нагружая его дополнительными функциями.

В данной работе мы предлагаем описывать невербальные движения с точки зрения тех механизмов управления поведением, которые могут привести к появлению данного движения в поведении. Такой «генеративный» подход может использоваться в качестве альтернативной классификации коммуникативных движений, а также - для разработки роботов и компьютерных агентов, ориентированных на общение с человеком [9]. Основное назначение нашего подхода - это представить данную классификацию в качестве индекса будущего словаря элементов невербальной коммуникации, выполняемого на основе корпуса REC [6].

\section{2 Генеративная модель классификации элементов невербальной коммуникации}

Предлагаемая модель представляет коммуникативное движение $S$ как функцию от эмоционального состояния, коммуникативной цели и референции. Такая модель для определённого движения S показывает варианты того, как $S$ могло бы быть порождено в коммуникации. Однако если в реальном поведении мы наблюдаем движение $S$, то данная модель не может точно подсказать, как это движение было порождено конкретным человеком в конкретном контексте: если при 
синтезе движения его источник точно определён, то при анализе движения в корпусе остаётся существенная омонимия.

Предлагаемая генеративная модель классифицирует коммуникативные движения на основании причины их порождения - их возможного стимула. При этом наша модель во многом опирается на модель эмоций OCC - Ortony, Clore, Collins [8], где эмоции делятся на три класса в зависимости от типа эмоциогенного стимула. Простые эмоции (любовь или отвращение) вызваны отдельным объектом: он нам приятен или неприятен. Эмоции второго класса вызваны действиями людей: мы гордимся или стыдимся собственных действий, восхищаемся действиями других или осуждаем их. Эмоции третьего класса вызваны последовательностями действий, распределённых во времени: мы испытываем облегчение, если ожидаемое негативное событие не наступило и т. д. С одной стороны, коммуникативные движения могут неконтролируемо порождаться внутренними состояниями, подобно эмоциональной экспрессии. С другой стороны, коммуникативные движения могут рационально контролироваться субъектом и использоваться в коммуникации с конкретной целью. Человек может использовать жест, чтобы сообщить своё коммуникативное намерение $I$, описать объект реального мира $O$ или воздействовать на адресата, вызвав у него реакцию $R$. В целях воздействия человек может специально усиливать экспрессию эмоций, «разыгрывая» эмоциональные роли в диалоге и имитируя эмоциональные состояния, чтобы сделать свою коммуникацию успешнее. Комбинация простых эмоциональных состояний и изменения уровня субъективного контроля позволяют нам описать континуум элементов невербальной коммуникации. Мы будем выделять 4 типа коммуникативных движений в зависимости от их исходного стимула.

\section{1 Выражение смысла и коммуникативного действия}

Будем отталкиваться от классической модели коммуникации [17]: пусть некий адресант передаёт адресату высказывание $U$ и сопровождает его невербальным действием $S$ - жестом, движением тела или мимическим паттерном (см. рис. 1). При этом адресат стремится реализовать коммуникативное намерение ${ }^{2} I$ : выполнить коммуникативное действие ${ }^{3}$ или описать объект $O^{4}$, пытаясь в результате достичь реакции $R$ адресата ${ }^{5}$. Если движение $S$ сопровождает высказывание $U$, то оно аналогично по функции речевым высказываниям и соответствует классу эмблематических жестов: оно может иконически описывать объект $O$ или составлять коммуникативное действие, например махать рукой на прощание или поднять большой палец вверх в качестве знака одобрения.

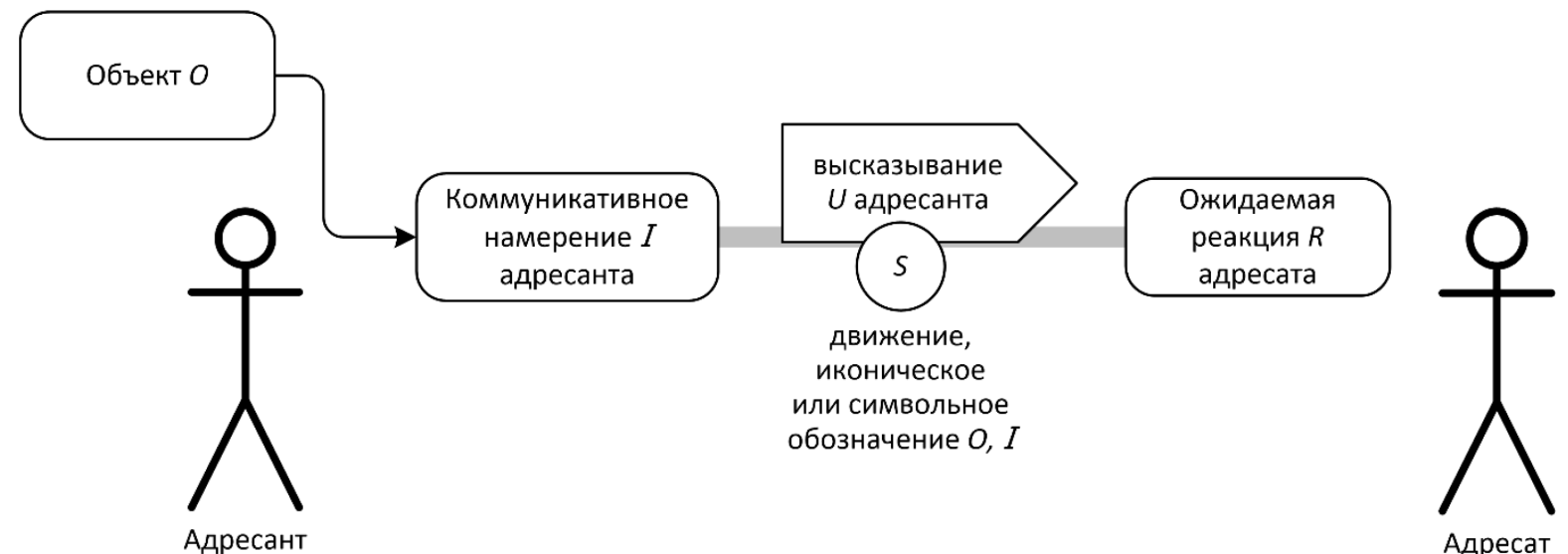

Рисунок 1: Коммуникативные движения, тип 1

\footnotetext{
2 При описании коммуникации мы используем термин коммуникативное намерение как аналог термина иллокутивная иель.

${ }^{3}$ Реализовать директивный, комиссивный или декларативный речевой акт.

${ }^{4}$ То есть реализовать ассертивный речевой акт.

5 То есть преследуя данную перлокутивную цель.
} 
Современные подходы к моделированию невербального поведения на основе нейросетей представляют жесты как функцию от высказывания $(S=\mathrm{f}(U))$. Этот подход демонстрирует достаточно хорошие результаты для моделирования жестов постоянно говорящего человека, например телеведущего [3]. Вместе с тем реальные примеры коммуникации показывают, что невербальное поведение характерно и для пауз, а жесты могут полностью заменять высказывания. По этой причине мы описываем высказывание $U$ и движение $S$ как функции от внутреннего состояния $I$, либо как функции от ожидаемой реакции $R$, на которую ориентировано сообщение. Движения для даного типа приведены в таблице 1.

\begin{tabular}{|c|c|}
\hline Стимул движения & Коммуникативное движение \\
\hline $\begin{array}{l}I=\text { коммуникативное } \\
\text { действие }\end{array}$ & $\begin{array}{l}\text { - жесты, обладающие словарной семантикой [12], выражаю- } \\
\text { щие определённое коммуникативное действие: взмах рукой } \\
\text { на прощание, поднятый вверх палец и т. д. }\end{array}$ \\
\hline $\begin{array}{l}O=\text { объект или ситуация } \\
I=\text { ассертивное сообщение: } \\
\text { описание объекта }\end{array}$ & $\begin{array}{l}\text { - иконические описания объекта: изображение его формы, } \\
\text { пути или способа перемещения, изображение отношения } \\
\text { межу объектами }\end{array}$ \\
\hline
\end{tabular}




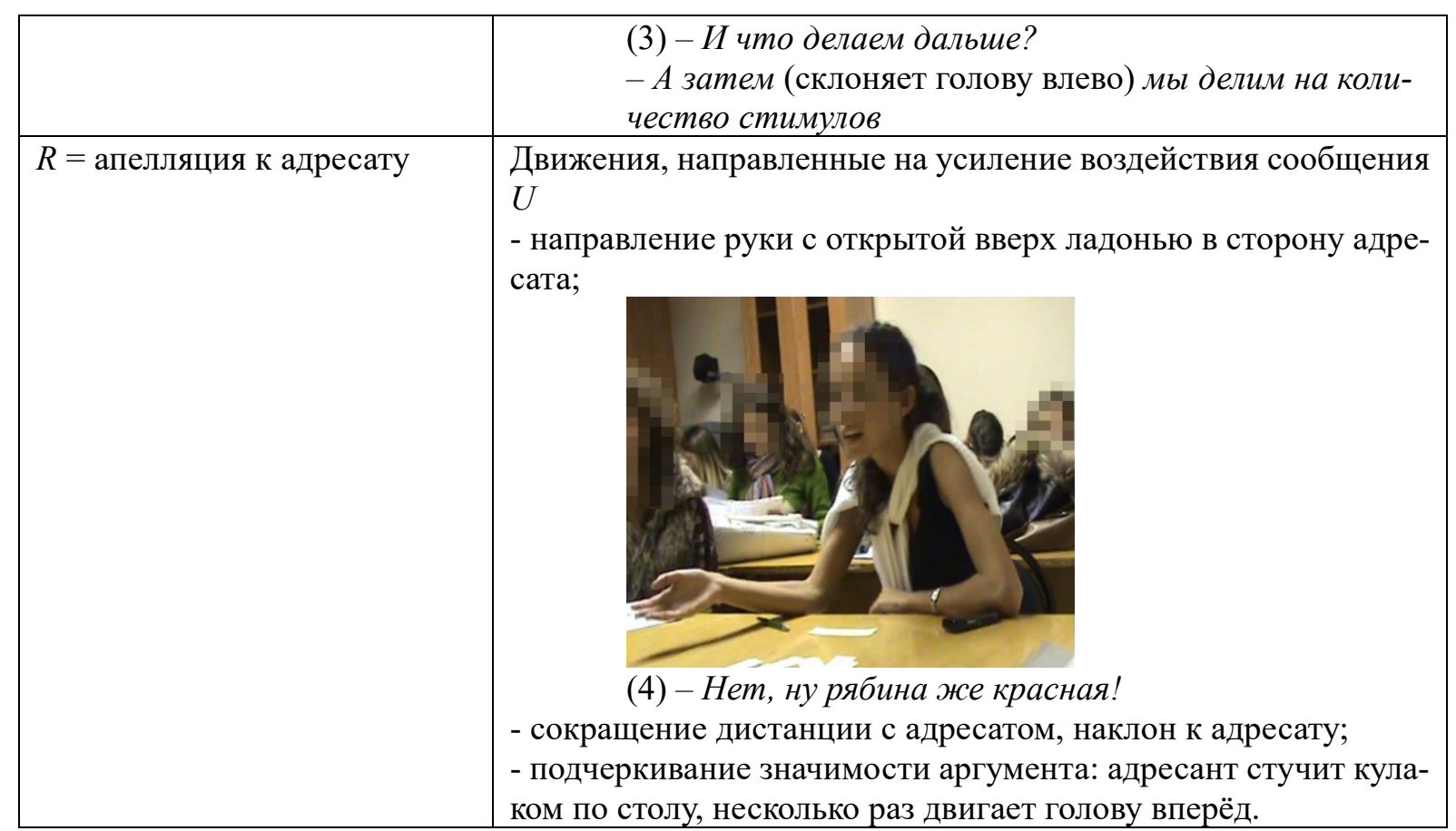

Таблица 1: Коммуникативные движения, тип 1

\section{2 Движения, связанные с реакциями и эмоциями}

Хотя жесты, выражающие коммуникативное намерение или обозначающие денотат, являются привычным материалом для лингвистики, базовый стимул для коммуникативных движений - это всё же эмоции и инстинкты. В этологии действия организма обычно представляются как вызванные четырьмя инстинктами: страхом, агрессией, сексуальным желанием или голодом [15], в силу своей простоты и возможности алгоритмизации такие модели широко используются при создании компьютерных моделей [11]. Психология при описании мимики ставит на первое место эмоции, выделяя для каждой эмоции типичные мимические паттерны выражения [13], например поднятие бровей для выражения удивления. В естественной коммуникации мы можем наблюдать множество почёсываний, облизываний, автоманипулирования (когда человек теребит одежду или волосы), изменения позы. В простом случае можно считать, что данные действия порождены неудовлетворённостью или локальным раздражением: если губы пересохли, нужно их облизать, если чешется рука, нужно её почесать. Эмоции могут быть вызваны не только эндогенным стимулом, но также внешним объектом или действиями другого человека - это позволяет при выражении эмоции выполнять референцию, ссылаться на эмоциогенный стимул. Наконец, выражение эмоций в коммуникации может влиять на адресата; способность воздействия на других людей может учить субъекта подавлять нежелательные эмоции и, наоборот, усиленно выражать те эмоции, которые нужным образом воздействуют на адресата. То есть выражение эмоций может иметь не реактивный, а целеориентированный характер. Рассмотрим эти варианты.

Непроизвольные движения. Коммуникативное движение $S$ может быть вызвано эндогенным стимулом - эмоциональным или физиологическим переживанием $I$ (рис. 2). Причиной этого состояния может быть физический раздражитель $I R$ : у нас заболел живот, мы порезали палец и т. д. Если состояние $I$ - это эмоциональное переживание, то, согласно модели ОСС, оно может быть вызвано отдельным объектом $O$ (например, отвращение может быть вызвано запахом тухлых продуктов) или действиями другого человека, в нашем случае - собеседника (действия $A$ ). Реакция на боль или на неприятный запах часто непроизвольна - то есть состояние $I$ автоматически вызывает движение $S$, которое сообщает, что адресант испытывает негативное переживание $I$, возможно, вызванное некоторой причиной: $O$, $I R$ или $A$. Таким образом, $S$ становится непроизвольным знаком, обозначающим для адресата состояние $I$, а также способным передавать субъективную оценку источника переживания: $O, I R$ или $A$. В результате $S$ получает способность к референции и может указывать на объекты реального мира $O$ или действия собеседника $A$. 
Произвольные движения. Хотя исходно физиологически обусловленные и эмоциональные движения - непроизвольны, адресант может пытаться подчинить их рациональному контролю так, что те же самые движения становятся произвольными. Если адресант осознаёт и пытается контролировать $S$, то он будет стремиться увеличить позитивный ${ }^{6}$ эффект для адресата. В этом случае говорящий опирается на модель адресата и прогнозирует его реакции $R$. С одной стороны, говорящий будет подавлять такие $S$, которые приведут к нежелательной реакции. С другой стороны, говорящий может намеренно усиливать выражение $S$, чтобы вызвать требуемую реакцию $R$. Такой контроль над экспрессией в области психологии эмоций обозначается как разделение вынужденных push-эмоций - они выражаются неконтролируемо, и преувеличенных pull-эмоций - они специально преувеличиваются адресантом, чтобы произвести воздействие на адресата [10].

Преувеличенная экспрессия $S$ позволяет адресанту лучше контролировать передачу информации: намеренно обозначить своё состояние $I R$, передавать адресату оценку действий $A$ или ссылаться с помощью жестов на объект $O$. Таким образом, повышение контроля над экспрессией $I$ и над воздействием на адресата $(I \rightarrow S \rightarrow R)$ позволяет произвольно выполнять референцию к объектам реального мира $O$ (денотатам), а также к субъективным состояниям $I R$. Выражение $S$ с усиленной экспрессией определяется, таким образом, двумя причинами: исходной активизацией состояния $I$ и ориентацией на воздействие на адресата $R$. Если же адресант полностью имитирует состояние $I$ и связанную с ним экспрессию $S$, то мы будем считать это случаем «эксплуатации» состояния I (см. далее). Движения для данного типа приведены в таблице 2.

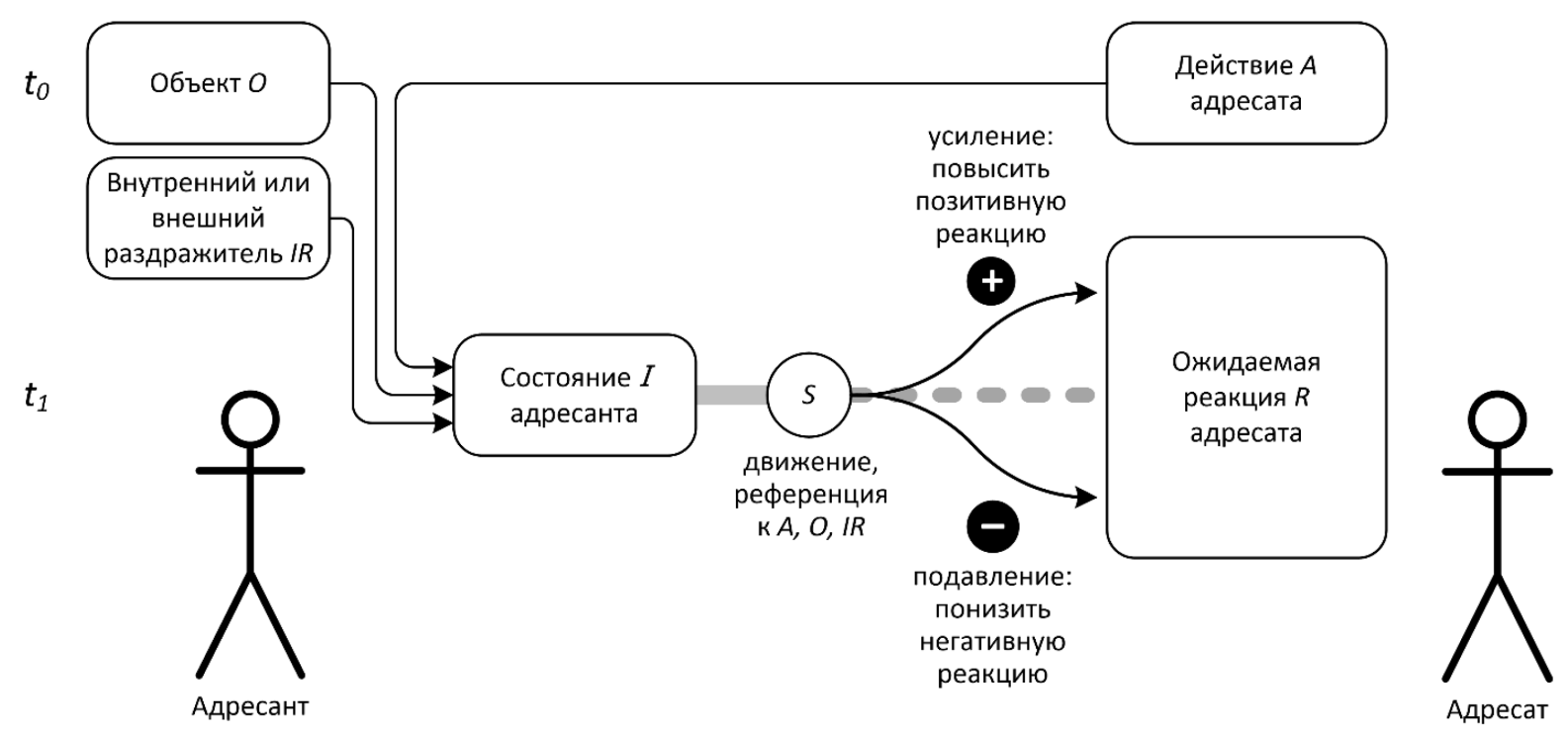

Рисунок 2: Коммуникативные движения, тип 2

\begin{tabular}{|l|c|}
\hline \multicolumn{1}{|c|}{ Стимул движения } & Коммуникативное движение \\
\hline$O / A$ = позитивный/негатив- \\
ный объект или ситуация \\
$I=$ радость или фрустрация & - радость, фрустрация \\
& (5)- Можно за зачёт сразу засчитать! \\
& -Ура! (машет руками) \\
\hline
\end{tabular}

${ }^{6}$ Под позитивнымм эффектом мы понимаем эффект, желательный для адресанта. 


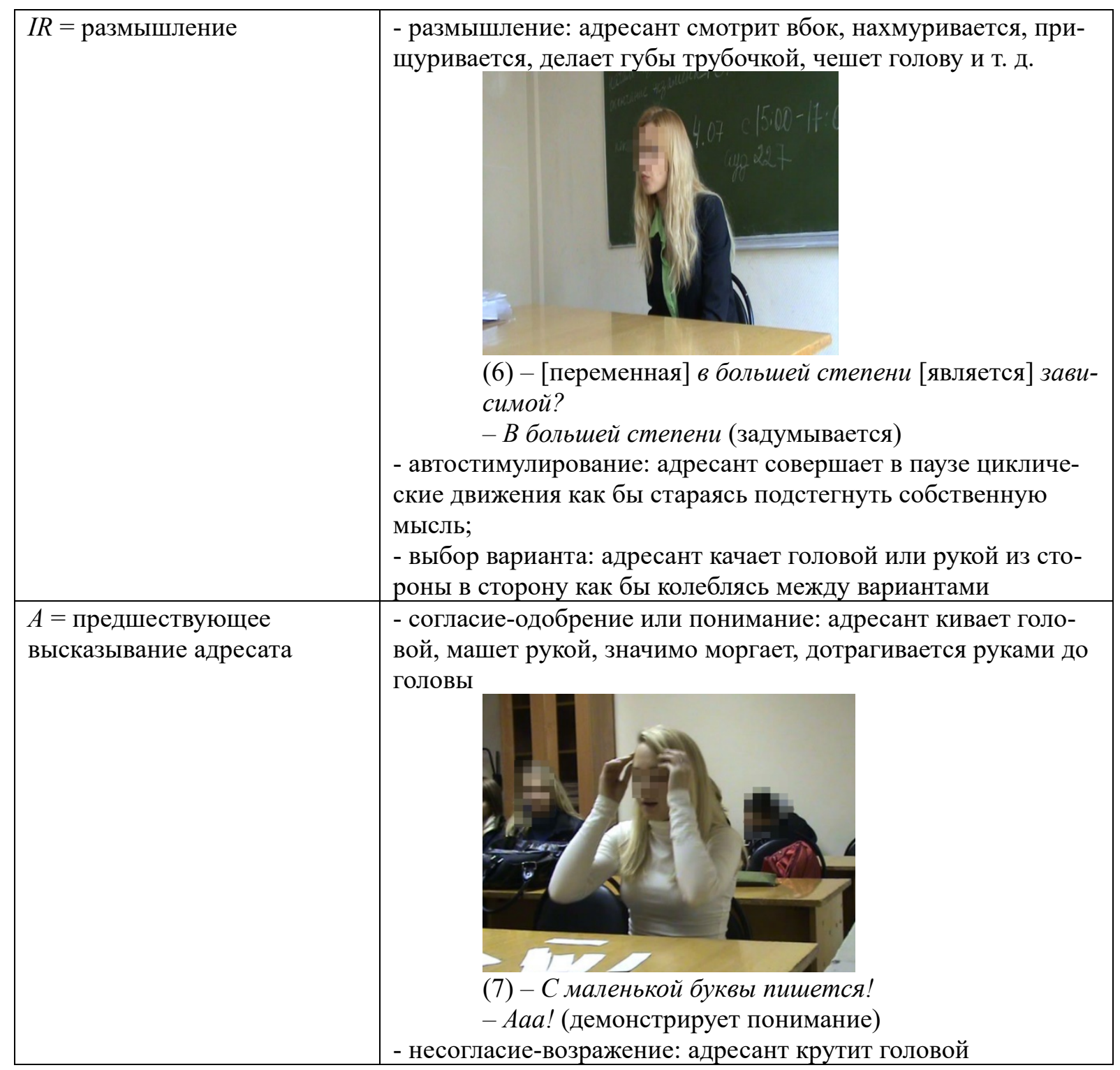

Таблица 2: Коммуникативные движения, тип 2

\section{3 Эксплуатация состояний}

Если выражение $S$ некоторого состояния $I$ регулярно вызывает у адресата требуемую реакцию $R$, то говорящий может освоить эту стратегию: специально выражать $S$, когда требуется воздействовать на адресата заданным образом. В этом случае будем говорить, что внутреннее состояние эксплуатируется (обозначим это ${ }^{\wedge} I$ ), то есть что адресат на самом деле не переживает $I$, а только использует его экспрессию $S$, чтобы повлиять на адресата и вызвать $R$. 


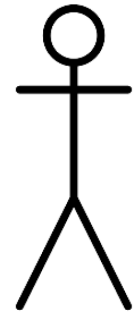

Адресант

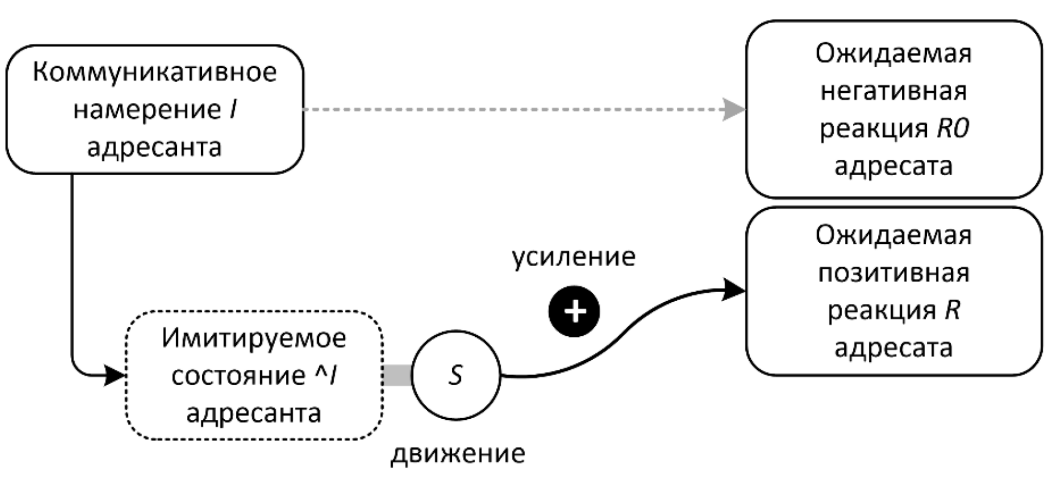

движение

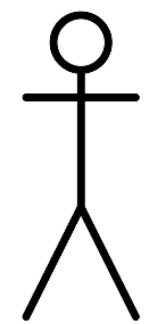

Адресат

Рисунок 3: Коммуникативные движения, тип 3

В целом случай эксплуатации состояний структурно похож на усиление эмоций (движения типа 2). С точки зрения анализа эмоций нельзя ставить вопрос о том, была ли эмоциональная экспрессия сымитирована или лишь преувеличена адресантом. Вместе с тем, с точки зрения синтеза, эксплуатация эмоций является перспективным методом развития экспрессии компьютерных агентов. В работе [7] был продемонстрирован компьютерный агент Greta, имитирующий гнев, чтобы скрыть испытываемую эмоцию грусти. В этом случае механизм порождения экспрессии гнева состоит в том, что исходное состояние (грусть) оценивается как невыгодное в коммуникации (вызовет негативную реакцию $R O$ ) и приводит к имитации эмоции гнева, скрывающей $I$ или должным образом воздействующей на адресата.

Концепция эксплуатации эмоциональных состояний важна для описания коммуникативных движений, поскольку при оценке высказываний оппонента адресант часто имитирует презрение или отвращение - то есть эмоции, исходно связанные с физическими объектами $O$. Движения для даного типа приведены в таблице 3.

\begin{tabular}{|c|c|}
\hline Стимул движения & Коммуникативное движение \\
\hline $\begin{array}{l}A=\text { негативно оцениваемое } \\
\text { суждение }\end{array}$ & $\begin{array}{l}\text { - говорящий хмурит брови, отворачивает голову или закры- } \\
\text { вает лицо, имитирует уход из коммуникации, чтобы проде- } \\
\text { монстрировать негативную оценку исходного тезиса } A\end{array}$ \\
\hline $\begin{array}{l}O=\text { неважный объект } \\
A=\text { неважная ситуация }\end{array}$ & $\begin{array}{l}\text { - преуменьшение значимости, пренебрежение - говорящий } \\
\text { машет рукой, имитирует плевок, прищуривается и морщит } \\
\text { нос; говорящий стремится убедить адресата сделать некото- } \\
\text { рое действие, потому что «оно не так уж важно» }\end{array}$ \\
\hline $\begin{array}{l}R=\text { принятие решения } \\
\text { адресатом }\end{array}$ & $\begin{array}{l}-\wedge I=\text { имитация усталости, страданий - адресант имитирует } \\
\text { усталость и отчаяние, чтобы продемонстрировать сложность } \\
\text { своей ситуации и спровоцировать адресата принять необходи- } \\
\text { мое решение } R\end{array}$ \\
\hline
\end{tabular}

Таблица 3: Коммуникативные движения, тип 3 


\section{4 Эффект от собственного высказывания}

В модели ОСС эмоции отдельного класса вызываются ожиданием негативных или позитивных событий: субъект может испытывать разочарование из-за того, что позитивные ожидания не оправдались, или, к примеру, облегчение - из-за того, что не оправдались его опасения. Диалог является именно такой ситуацией, которая разворачивается во времени и в которой говорящий может предвосхищать эффект собственных слов, в частности, предполагать негативную реакцию $R 0$ адресата на собственные слова $U$. С помощью движения $S$ адресант будет стараться компенсировать негативный эффект своих слов или выражать собственные переживания из-за $U .{ }^{7}$ Ради этого говорящий может придумать и эксплуатировать состояние ${ }^{\wedge} I$, даже если он на самом деле его не переживает: 'я вынужден сказать $U$, это неприятно $(R 0)$ для адресата, поэтому я имитирую смущение ${ }^{\wedge} I$, чтобы позитивно воздействовать $(R)$ на адресата и снизить впечатление от моих слов'.

Попытка распознать эффект $R 0$ собственных слов $U$ - это обратная связь для адресанта. Если адресат не реагирует на сообщение $U$ и не отвечает требуемым действием, то такое отсутствие $(R 0)$ обратной связи, тоже является негативным событием для говорящего: говорящий может повторять собственное высказывание, демонстрировать жесты, повторяющие семантику высказывания, сокращать дистанцию до адресата, чтобы спровоцировать того предоставить реакцию на сообщение $U$. Движения для данного типа приведены в таблице 4.

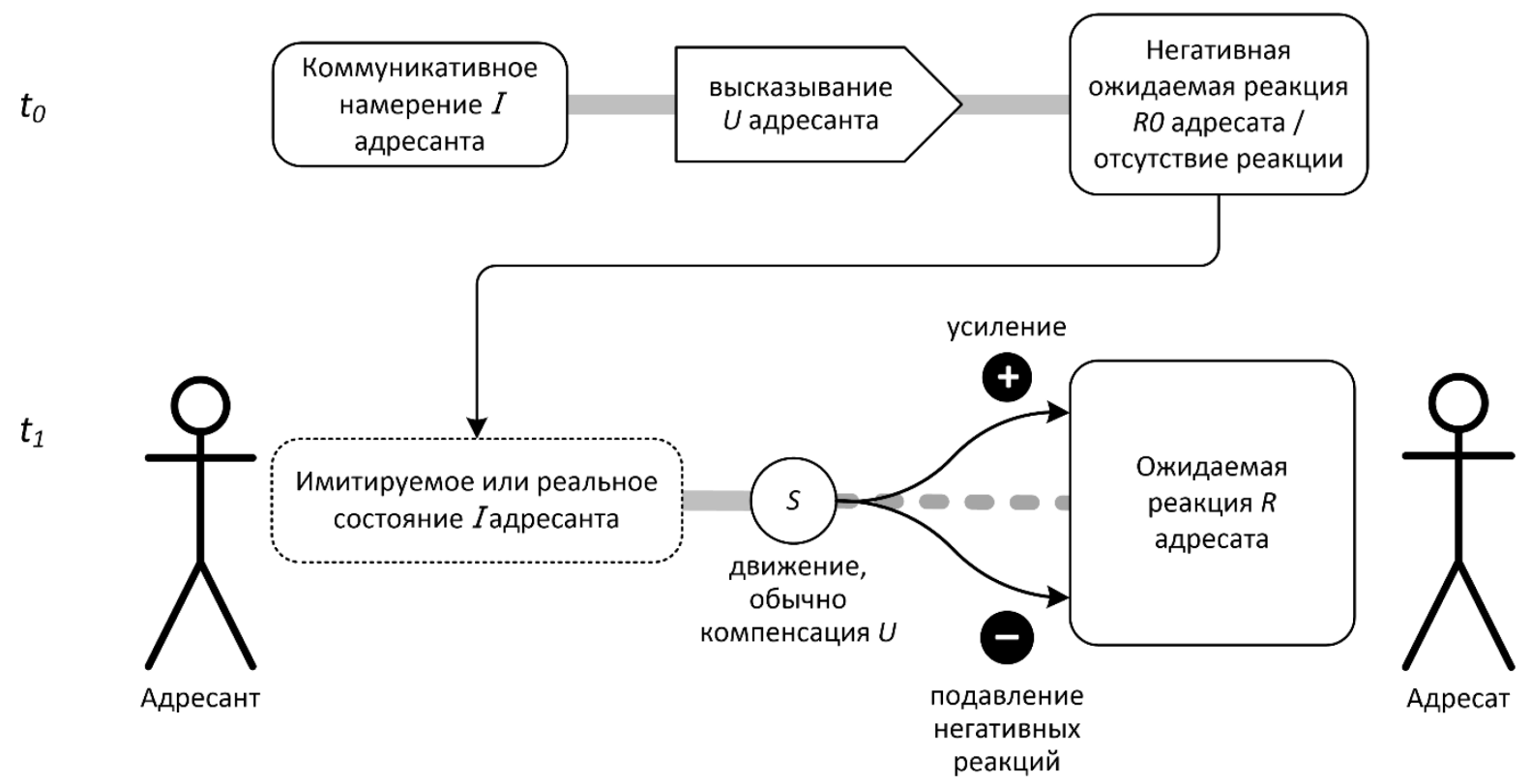

Рисунок 4: Коммуникативные движения, тип 4

\footnotetext{
${ }^{7}$ Аналогичный механизм описан в теории вежливости [1]. Если адресат вынужден выразить в речи действие, затрагивающее лиио адресата (face threatening act-FTA), он также будет сопровождать свою речь стратегиями негативной и позитивной вежливости, например демонстрировать собственные переживания из-за необходимости побеспокоить адресата.
} 


\begin{tabular}{|c|c|}
\hline $\begin{array}{l}I=\text { смущение, } \\
R=\text { компенсация сму- } \\
\text { щения }\end{array}$ & $\begin{array}{l}\text { - высказывание, в успешности которого человек сомневается, мо- } \\
\text { жет заставлять его испытывать смущение и выражать его с помо- } \\
\text { щью автоманипулирования (теребить одежду, волосы), закрытой } \\
\text { позы, сжатых губ; }\end{array}$ \\
\hline $\begin{array}{l}R 0=\text { непонимание } \\
R=\text { полное понимание } \\
\text { текста }\end{array}$ & $\begin{array}{l}\text { - адресант сомневается, что адресат понял высказывание } U, \text { по- } \\
\text { этому дополняет своё высказывание жестами, повторяющими или } \\
\text { подчёркивающими смысл высказывания } U\end{array}$ \\
\hline $\begin{array}{l}R 0=\text { отсутствие реак- } \\
\text { ции на } U\end{array}$ & $\begin{array}{l}\text { - адресант ожидает обратной связи от адресата на высказывание } U \text {, } \\
\text { как считает адресант, высказывание } U \text { не было воспринято }(R 0) \text {, ад- } \\
\text { ресат не делает то, что он должен сделать при получении } U\end{array}$ \\
\hline
\end{tabular}

Таблица 4: Коммуникативные движения, тип 4

\section{3 Описание генеративной модели}

Предложенная классификация предполагает следующую генеративную модель.

(1) Если говорящий реализует коммуникативный акт $I$ или описывает объект $O$, он может порождать иконические жесты $S$ типа 1, выражающие $I$ или обозначающие признаки $O$.

(2) Раздражитель $I R$, внешний объект $O$ или действие собеседника $A$ могут вызывать у адресанта состояние $I$, которое адресант может непроизвольно выражать движениями $S$ типа 2 . Адресант может в некоторых пределах контролировать экспрессию $S$, чтобы оказать воздействие на адресата: подавить экспрессию негативных ${ }^{8}$ состояний $I$ или увеличить экспрессию позитивных состояний $I$, чтобы максимизировать позитивное воздействие $R$ на адресата.

(3) Если адресант намерен воздействовать на адресата - избежать негативной реакции $R 0$ и вызвать позитивную реакцию $R$ - то он может имитировать состояние ${ }^{\wedge} I$ и выражать типичную для него экспрессию $S$ типа 3 , чтобы максимизировать позитивное воздействие $R$ на адресата. При этом адресант использует знания о том, как выражение различных состояний $I$ обычно влияет на адресата коммуникации.

(4) Если адресант сообщает высказывание $U$, то это может вызвать состояние $I$ адресанта, выражаемые движениями $S$ типа 4 . Если адресант ожидает негативной реакции $R 0$ на своё сообщение $U$, наблюдает такую реакцию или не наблюдает требуемой реакции, он может активизировать или имитировать состояние $I$, чтобы максимизировать позитивное воздействие $R$ на адресата.

\section{4 Заключение}

Хотя элементы невербального поведения в коммуникации и обладают существенным разнообразием, они могут быть представлены в виде структурной классификации. Мы отталкиваемся от того, что каждое коммуникативное движение (от непроизвольных почесываний до словарных невербальных знаков) вызвано некоторым внутренним состоянием. Поэтому основу предложенной классификации составляют возможные пути, приводящие к активизации этого внутреннего состояния и, далее, к наблюдаемой экспрессии. Такая генеративная модель не может объяснить

\footnotetext{
${ }^{8}$ Термины негативный и позитивный означают в данном контексте - соответствующий намерению или оценке самого говорящего.
} 
причины конкретного движения, наблюдаемого в корпусе - имеется множество путей, каждый из которых мог бы привести к данному движению. Вместе с тем, данная модель потенциально позволяет классифицировать все множество движений, наблюдаемых в коммуникации, и служит проектом индекса для словаря невербального поведения по материалам корпуса REC. A поскольку классификация проводится по стимулам и путям возникновения движения, данная модель может быть адаптирована для управления невербальным поведением роботов и компьютерных агентов, поддерживающих общение с человеком с помощью речи и невербальных средств.

\section{Литература}

[1] Brown Penelope, Levinson Stephen C., Levinson Stephen C. Politeness: Some universals in language usage (Studies in Interactional Sociolinguistics). - Cambridge university press, 1987. - Vol. 4.

[2] Efron David: Gesture, Race and Culture. - Mouton, 1972.

[3] Ginosar Shiry et al. Learning individual styles of conversational gesture // Proceedings of the IEEE/CVF Conference on Computer Vision and Pattern Recognition. - 2019. - P. 3497-3506.

[4] Iriskhanova Olga K., Cienki A.: The semiotics of gestures in cognitive linguistics: contribution and challenges. - Vopr. Kognitivnoy Lingvistiki, 2018.

[5] Kendon Adam: Nonverbal Communication: Interaction and Gesture. - The Hague: Mouton Publisher, 1981.

[6] Kotov Artemy, Budyanskaya Elena: The Russian emotional corpus: communication in natural emotional situations // Computational Linguistics and Intellectual Technologies. - 2012. - Vol. 11. - №. 18. - P. 296-306.

[7] Ochs Magalie. et al. Intelligent expressions of emotions // International Conference on Affective Computing and Intelligent Interaction. - Springer, Berlin, Heidelberg, 2005. - P. 707-714.

[8] Ortony Andrew, Clore Gerald L., Collins Allan: The cognitive structure of emotions. - Cambridge university press, 1990.

[9] Rehm Matthias, André Elisabeth: From annotated multimodal corpora to simulated human-like behaviors // Modeling communication with robots and virtual humans. - Springer, Berlin, Heidelberg, 2008. - P. 1-17.

[10] Scherer Ursula, Helfrich Hede, Scherer Klaus R.: Paralinguistic behaviour: Internal push or external pull? // Language. - Pergamon, 1980. - P. 279-282.

[11] Sloman Aaron: Beyond shallow models of emotion // Cognitive Processing. - 2001. - Vol. 2. - №. 1. P. 177-198.

[12] Григорьева Светлана А., Григорьев Николай В., Крейдлин Григорий Е. Словарь языка русских жестов. - Языки русской культуры, 2001.

[13] Изард Кэррол Е.: Эмоции человека: Пер. с англ. - Изд-во Моск. ун-та, 1980.

[14] Крейдлин Григорий. В. Невербальная семиотика: язык тела и естественный язык. - М.: Новое лит. Обозрение, 2002.

[15] Лоренц Конрад: Оборотная сторона зеркала. М.: Республика. - 1998.

[16] Николаева Юлия В., Кибрик Андрей А., Федорова Ольга В.: Структура устного дискурса: взгляд со стороны мультимодальной лингвистики // Компьютерная лингвистика и интеллектуальные технологии. Диалог-2015. - 2015. - С. 487-489.

[17] Якобсон Роман: Лингвистика и поэтика // Структурализм: «За» и «против». - М.: 1975. 